\title{
Glioblastoma Multiforme and Angiogenesis: A Clinicopathological and Immunohistochemistry Approach
}

\author{
Martha Lilia Tena-Suck ${ }^{\mathrm{a}, \mathrm{f}}$, Miguel Angel Celis-Lopez ${ }^{\mathrm{b}}$, Miguel Angel Collado-Ortiz ${ }^{\mathrm{c}}$, \\ Manuel Castillejos-Lopez ${ }^{\mathrm{d}}$, Mariana Tenorio-Serralta ${ }^{\mathrm{e}}$
}

\begin{abstract}
Background: Glioblastomas multiforme (GBMs) are histologically heterogeneous tumors derived from highly vascularized glia. This microvascular proliferation is a biological key to diagnosis.

Methods: The purpose of this study was to analyze the immunohistochemistry features of these lesions, looking for commonly expressed antibodies such as vimentin, nestin, glial fibrillary acidic protein (GFAP), GFAP delta (GFAP- $\delta$ ), vascular endothelial growth factor (VEGF), VEGF receptor 2 (VEGF-R2), VIII factor, CD31, CD34 and CD15 in 80 cases of GBM patients with a 15 -month follow-up. Microvascular density (MVD) and Ki-67 labeling index (LI) were performed.

Results: Eighty patients' GBMs were surgically removed in 1 year with a 15-month follow-up, including 64 men (80\%) and 16 women $(20 \%)$. The age range was $37-87$ years (mean age $58.36 \pm 9.929$ years). Seventeen $(21 \%)$ cases were less than 50 years old $(\mathrm{P}=0.003)$. The range of age in men was 37 - 71 years (median age 56 years) and in women was $39-86$ years (median age 58 years). Thirty-five $(44 \%)$ cases had secondary tumors and $45(56 \%)$ had primary tumors. Survival time ranged between 14 and 60 weeks (mean $44.40 \pm 16.26$ weeks). Inflammation and necrosis were more common in primary than in secondary, also with one showing higher MVD index for VEGF, VEGF-R2, CD31 and CD34.
\end{abstract}

Manuscript accepted for publication May 18, 2015

aDepartment of Neuropathology, National Institute of Neurology and Neurosurgery, Mexico City, Mexico

bService of Neurosurgery, National Institute of Neurology and Neurosurgery, Mexico City, Mexico

${ }^{\mathrm{C} N e u r o l o g i c a l}$ Center, Department of Clinical Neurophysiology, The American British Cowdray Hospital, Mexico City, Mexico

${ }^{\mathrm{d} D e p a r t m e n t}$ of Epidemiology, National Institute of Respiratory Diseases, Mexico City, Mexico

eDepartment of Pathology, General (Civil) Hospital of Guadalajara Jalisco, Mexico

${ }^{f}$ Corresponding Author: Martha Lilia Tena-Suck, Department of Neuropathology, National Institute of Neurology and Neurosurgery, Av Insurgentes Sur 3877 Col. La Joya, Delegacion Tlalpan CP 14269, Mexico City, Mexico. Email:mltenasuck@gmail.com

doi: http://dx.doi.org/10.14740/jnr337w
Conclusion: Expression of nestin, vimentin, GFAP- $\delta$, VEGF, and VEGF-R2 peritumoral cells has bad prognosis in GBM.

Keywords: Angiogenesis; Glioblastoma multiforme; Immunohistochemistry; VEGF; VEGF-R2; Nestin; Vimentin; CD34; MVD

\section{Introduction}

Glioblastoma multiforme (GBM) is a grade IV glioma according to the World Health Organization (WHO) [1], accounts for $15 \%$ of all primary brain tumors and has a median survival range of less than 2 years after diagnosis, with a median survival time of only 15 months even after multimodal therapy [1]. It is highly invasive, making tumor recurrence certain even after a complete resection [2,3]. GBMs are histologically heterogeneous tumors derived from glia and highly vascularized by neoformed vessels, from which they are thought to arise by sprouting of pre-existing brain capillaries [1].

The tumor microenvironment plays a critical role in tumor initiation, invasion and progression. Microvascular proliferation is a biological key and diagnostic hallmark for human GBM [1-4]. It is believed that the reason for this poor outcome is the tumor's polyclonal composition clones of dividing tumor cells and tumor initiating cells. Neoangiogenesis is a crucial factor in the malignant tumoral behavior and prognosis of patients. Several mechanisms are suspected to lead to neoangiogenesis; one of them is the recruitment of multipotent progenitor cells towards the tumor $[4,5]$. It has recently been suggested that glioblastoma stem-like cells (GSCs) have the capacity to differentiate into functional endothelial cells, preferentially differentiating into vascular pericytes to support vasculature function and tumor growth differentiation and that a significant proportion of the vascular lining in tumors has a neoplastic origin [4-6]. Analysis of human GBM specimens showed that most pericytes are derived from neoplastic cells [7]. Because GSCs often reside in perivascular niches and may undergo mesenchymal differentiation. Normal neural stem cells are able to differentiate into functional endothelial cells. The connection between neural stem cells and the endothelial compartment seems to be critical in GBM, where cancer stem cells closely interact with the vascular niche and promote angiogenesis $[3-5,7,8]$. GSCs contribute to vascular pericytes 
Table 1. Clinical and Epidemiological Data of Patients Operated With Glioblastoma

\begin{tabular}{|c|c|c|c|c|c|c|}
\hline Clinical data & Primary $(n=35)$ & Secondary $(n=45)$ & P value & $<50$ years $(n=17)$ & $>50$ years $(n=63)$ & P value \\
\hline Age & 57 years & 58 years & 0.231 & 46 years & 61 years & 0.230 \\
\hline Female & $21(60)$ & $27(60)$ & 0.000 & $9(53)$ & $39(62)$ & 0.448 \\
\hline Simtoms upset & 40 months & 36 months & 0.000 & 24 months & 45 months & 0.737 \\
\hline Total exeresis & $12(43)$ & $12(27)$ & 0.544 & $5(29)$ & $19(30)$ & 0.004 \\
\hline Post treatment status & & & 0.220 & & & 0.140 \\
\hline Improvement & $6(17)$ & $6(13)$ & & $4(24)$ & $5(8)$ & \\
\hline Deterioration & $11(31)$ & $11(24)$ & & $6(35)$ & $16(25)$ & \\
\hline Unchanged & $4(11)$ & $30(67)$ & & $6(35)$ & $40(63)$ & \\
\hline Survival & 4 months & 2 months & 0.998 & 6 months & 2 months & 0.567 \\
\hline
\end{tabular}

The symptoms up onset, follow-up were calculated by median mounts. Age was also calculated by years and median.

that may actively remodel perivascular niches. Therapeutic targeting of GSC-derived pericytes may effectively block tumor progression and improve antiangiogenic therapy [7]. The current standard glioblastoma therapy includes surgery followed by concomitant radiation and chemotherapy with the DNA alkylating agent temozolomide (TMZ), producing a median survival of only 14.6 months [2].

The aim of this work was to study the angiogenic factors and stem cell markers, to evaluate whether the MIB-1 labeling index (LI) and microvascular density (MVD) in GBM could be used as useful markers for predicting the pattern of failure.

\section{Material and Methods}

\section{Clinical specimens}

In this study, 80 consecutive patients with histologically proven GBMs were retrospectively reviewed. These patients were treated with surgery and radiotherapy at the National Institute of Neurology and Neurosurgery in Mexico City. The retrospective review and the use of clinical data were approved by the institutional ethics committee. Cases were divided between patients $<50$ years and $>50$ years old, as well as primary and secondary tumors. Histopathological analysis was performed with particular emphasis on the presence of endothelial proliferation, glomeruloid vessels, inflammation and necrotic areas for each case. Tumors were graded according to the WHO [1].

\section{Immunohistochemistry}

Immunohistochemical analyses were performed on $4-\mu \mathrm{m}$ paraffin sections that were deparaffinized in xylene and rehydrated through a series of ethanol treatments. Antigen retrieval was accomplished by incubating the sections in $10 \mathrm{mmol} / \mathrm{L}$ sodium citrate $(\mathrm{pH} 6.0)$ and heating them for $10 \mathrm{~min}$ in a pressure cooker. To block endogenous peroxidase activity, sections were immersed for $30 \mathrm{~min}$ in a $6 \%$ hydrogen peroxide solution diluted in methanol (v/v) and were then washed with phosphate buffer solution ( $\mathrm{pH}$ 7.4). Proteins were blocked using CAS-Block (Zymed), and the stained cells were incubated at $37{ }^{\circ} \mathrm{C}$ for $30 \mathrm{~min}$ and then at $4{ }^{\circ} \mathrm{C}$ overnight. Sections were immunostained using the Vectastain ABC Elite Kit (Vector Laboratories, Burlingame, CA, USA): primary antibodies used were CD31, CD34, CD15, vascular endothelial growth factor (VEGF), VEGF receptor 2 (VEGF-R2), von Willebrand's factor (VIII factor), glial fibrillary acidic protein (GFAP), GFAP delta (GFAP- $\delta$ ), vimentin, and nestin according to the manufacturer's instructions for each one of monoclonal antibodies. The final visualization was carried out by chromogenic detection using a solution of phosphate buffer solution (PBS) containing $0.1 \%$ diaminobenzidine, $0.06 \% \mathrm{H}_{2} \mathrm{O}_{2}$ and $1 \%$ dimethyl sulfoxide. The sections were immersed in this solution for 5 min at $37{ }^{\circ} \mathrm{C}$. Counterstaining was performed using Harris hematoxylin stain. A known positive control was included and sections that were incubated with PBS instead of the primary antibody served as negative controls. Endothelial cells, wall of vessels, tumoral cells and tumoral perivascular cells were evaluated for each of the different primary antibodies used.

\section{Quantification of immunohistochemistry}

The LIs for all antibodies were calculated as a percentage of the positively stained nuclei. Normal adjacent brain tissue was excluded from analysis. The MIB-1 (Ki67-LI) was calcu- 
Table 2. Histological Features and Index According to Primary vs. Secondary Tumors and Age

\begin{tabular}{lllllll} 
& Primary $(\mathbf{n}=\mathbf{3 5})$ & Secondary $(\mathbf{n}=\mathbf{4 5})$ & P value & $<\mathbf{5 0}$ years $(\mathbf{n}=\mathbf{1 7})$ & $>\mathbf{5 0}$ years $(\mathbf{n}=\mathbf{6 3})$ & P value \\
\hline Necrosis & $23(66)$ & $37(82)$ & 0.091 & $11(65)$ & $49(78)$ & 0.123 \\
Inflammation & $11(31)$ & $25(56)$ & 0.031 & $9(53)$ & $27(43)$ & 3 \\
Mitosis index & 3 & 3 & 0.521 & 4 & 20 & 0.458 \\
Ki67-LI & 18 & 19 & 0.033 & 18 & 65 & 0.549 \\
MVD (CD31) & 65 & 62 & 0.506 & 58 & 89 & 0.117 \\
MVD (CD34) & 70 & 79 & 0.000 & 71 & 0.037 \\
\hline
\end{tabular}

Mitosis index, MIB-1 index and microvascular density index were calculated by median.

lated as the percentage of positively stained tumor cell nuclei among 1,000 nuclei detected in areas with the greatest degree of immunostaining in the areas with highest density of positive nuclei (at least 10 representative microscopic fields) under $\times$ 400 magnification. The MVD LI was also counted for CD31, CD34, C15, factor VIII, nestin, VEGF, VEGF-R2, GFAP and GFAP- $\delta$. Mean, median and standard deviation of the Ki67-LI and MVD LI were used as a reference to establish a cut-off point.

\section{Statistical analysis}

All statistical analyses were performed with SPSS version 20.0 (SPSS, Chicago, IL, USA). Categorical variables were compared using Fisher's exact test and P values $<0.05$ were considered statistically significant. In the follow-up evaluations, local and systemic tumor control was assessed at 1 - 15-month intervals using magnetic resonance imaging (MRI). Progression-free survival (PFS) and overall survival (OS) rates were analyzed statistically in all patients. PFS was calculated from the first day of radiotherapy to the date of any recurrence or death, or censored at the date of the last follow-up. OS was calculated from the first day of radiotherapy to the date of death or censored at the date of the last follow-up and calculations were made using Kaplan-Meier estimates. Statistical significance was determined using the log-rank test. The Chi-square test was used for the comparisons among cohorts in this analysis.

\section{Results}

\section{Clinical results}

The clinical and demographic characteristics of patients according to primary vs. secondary tumors are shown in Table 1. In 80 patients, GBMs were surgically removed in 1 year with a 15-month follow-up, including 64 men (80\%) and 16 women $(20 \%)$. The age range was between 37 and 87 years (mean age $58.36 \pm 9.929$ years). Seventeen $(21 \%)$ cases were less than 50 years old $(\mathrm{P}=0.003)$. The range of age in men was between 37 and 71 years old (median age 56 years) and in women between 39 and 86 years old (median age 58 years). Thirty-five (44\%) cases had history of glioma (secondary tumor) and $45(56 \%)$ had primary tumors. Seventeen $(21 \%)$ cases were less than 50 years old and $63(79 \%)$ patients were over 50 years $(P=0.003)$. Survival time ranged between 14 and 60 weeks (mean $44.40 \pm 16.26$ weeks). Survival time for men was $64 \pm 4.92$ and for women was $50.0 \pm 5.35$ weeks. The symptoms onset ranged between 7 and 73 days (median 58.17 days). Residual tumor was present in $22(90 \%)$ patients and $25(90 \%)$ relapsed in 15 months. Twenty (67\%) patients required a second surgery.

\section{Immunohistochemical results}

The summarized results are seen in Table 2. Figures 1 and 2 show the results of different antibodies used in relation tumoral cells and perivascular areas. The Ki67-LI was $12-33 \%$ (mean $18.17 \pm 4.85 \% ; 18.14 \pm 5.10 \%$ for men and $18.25 \pm 4.44 \%$ for women) $(\mathrm{P}=0.044)$. In patients less than 50 years old, it was $23.86 \pm 4.63 \%$ and in patients older than 50 years, it was $16.43 \pm 3.34 \%(\mathrm{P}=0.000)$. The MIB-1 LI for tumors having a previous glioma was $18.78 \pm 6.66 \%$ vs. non-previous glioma $17.90 \pm 4.20 \%(\mathrm{P}=0.004)$. Table 3 shows the median indexes of both perivascular and tumor positive cells to different primary antibodies used. Figure 3a shows the Kaplan-Meier curves in relationship with nestin and GFAP immunoexpression and the follow-up of the patients. Figure $3 \mathrm{~b}$ shows the relation between patients $<50$ years and $>50$ years and survival, Figure $3 \mathrm{c}$ shows the relation between recurrence and follow-up and Figure $3 \mathrm{~d}$ shows the survival of the patients at 15 months.

\section{Clinicopathological correlation}

There was relationship between nausea and vomit $(\mathrm{P}=0.000)$, and motor symptoms $(\mathrm{P}=0.002)$, and more cell intensity was observed in previous glioma or secondary glioma than the primary one $(\mathrm{P}=0.017)$, relapse $(\mathrm{P}=0.004)$, nestin expression $(\mathrm{P}$ $=0.027)$ and perivascular nestin $(\mathrm{P}=0.041)$.

There was correlation between seizures and high levels of microvascular density $(\mathrm{P}=0.007)$, glomeruloid vessels $(\mathrm{P}$ $=0.000)$, small cells $(P=0.000)$, calcifications $(P=0.000)$, nestin $(\mathrm{P}=0.017)$, perivascular positive nestin cells, perivascular GFAP- $\delta(\mathrm{P}=0.000)$, perivascular CD15 $(\mathrm{P}=0.000)$, tumoral cells CD31 positive $(\mathrm{P}=0.000)$, perivascular VEGF $(\mathrm{P}$ $=0.000)$, perivascular VEGF-R2 $(\mathrm{P}=0.000)$ and Ki67-LI $(\mathrm{P}$ 


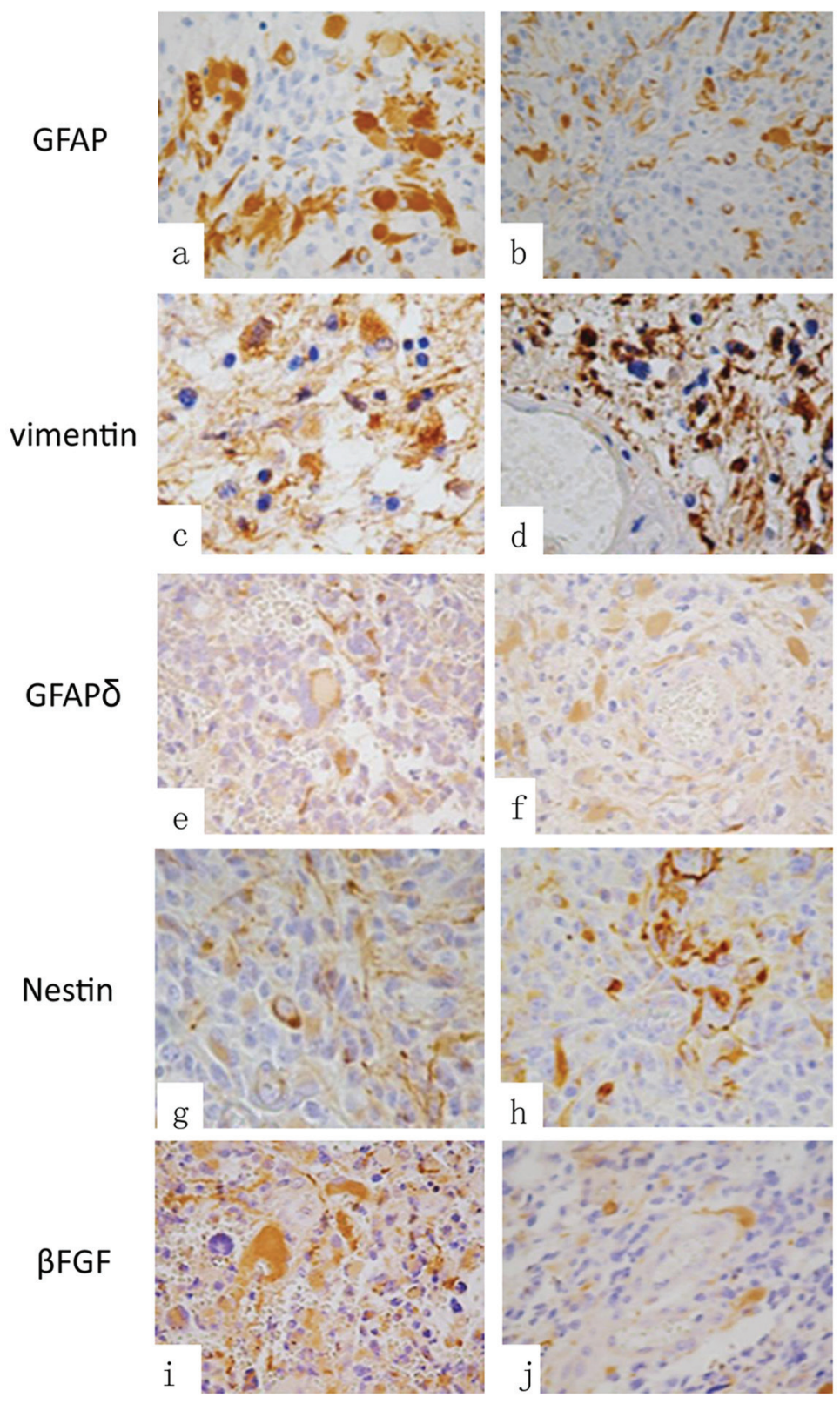

Figure 1. Immunohistochemistry: (a) GFAP in tumor cells, (b) GFAP in perivascular cells, (c) vimentin in cells, (d) perivascular vimentin, (e) GFAP- $\delta$ in tumoral cells and in (f) GFAP- $\delta$ expression in perivascular cells. (g) Expression of nestin positive cells in tumoral areas and (h) nestin positive perivascular cells. (i) Expression of $\beta F G F$ in tumoral cells and in (j) observed $\beta F G F$ positive immunoreaction in peritumoral cells (original magnification $\times 400$ ).

$=0.021)$.

Fifteen months relapse was correlated with personality disorders $(\mathrm{P}=0.029)$, nestin positive expression $(\mathrm{P}=0.48)$, perivascular GFAP intensity $(\mathrm{P}=0.048)$, cytoplasmic C-kit $(\mathrm{P}$ $=0.000)$, perivascular VEGF $(\mathrm{P}=0.000)$, VEGF intensity in tumoral cells $(\mathrm{P}=0.011)$, perivascular VEGF-R2 $(\mathrm{P}=0.000)$, vascular VEGF-R2 $(\mathrm{P}=0.027)$, Ki67-LI $(\mathrm{P}=0.041)$ and age $(\mathrm{P}=0.037)$.

There was a correlation between Ki67-LI plus seizures (P $=0.017), 15$ months relapse $(\mathrm{P}=0.041)$, clinical deterioration
( $P=0.030)$, survival $(P=0.024)$, necrosis $(P=0.018)$, vascular endothelial proliferation $(\mathrm{P}=0.018)$, tumoral cells nestin expression $(\mathrm{P}=0.016)$, nestin expression in vessels $(\mathrm{P}=$ $0.035)$, perivascular nestin $(\mathrm{P}=0.028)$, GFAP expression ( $\mathrm{P}$ $=0.039)$, GFAP positive cells intensity $(\mathrm{P}=0.032)$, GFAP- $\delta$ intensity in perivascular cells $(\mathrm{P}=0.003)$, intracytoplasmic $\mathrm{C}$ kit $(\mathrm{P}=0.049)$, perivascular $\mathrm{CD} 15(\mathrm{P}=0.022)$, vascular $\mathrm{CD} 31$ $(\mathrm{P}=0.016)$, perivascular $\mathrm{CD} 34(\mathrm{P}=0.006)$, VEGF tumoral cells expression $(\mathrm{P}=0.048)$, VEGF in vessels $(\mathrm{P}=0.025)$ and VEGF-R2 in vessels $(\mathrm{P}=0.025)$. 


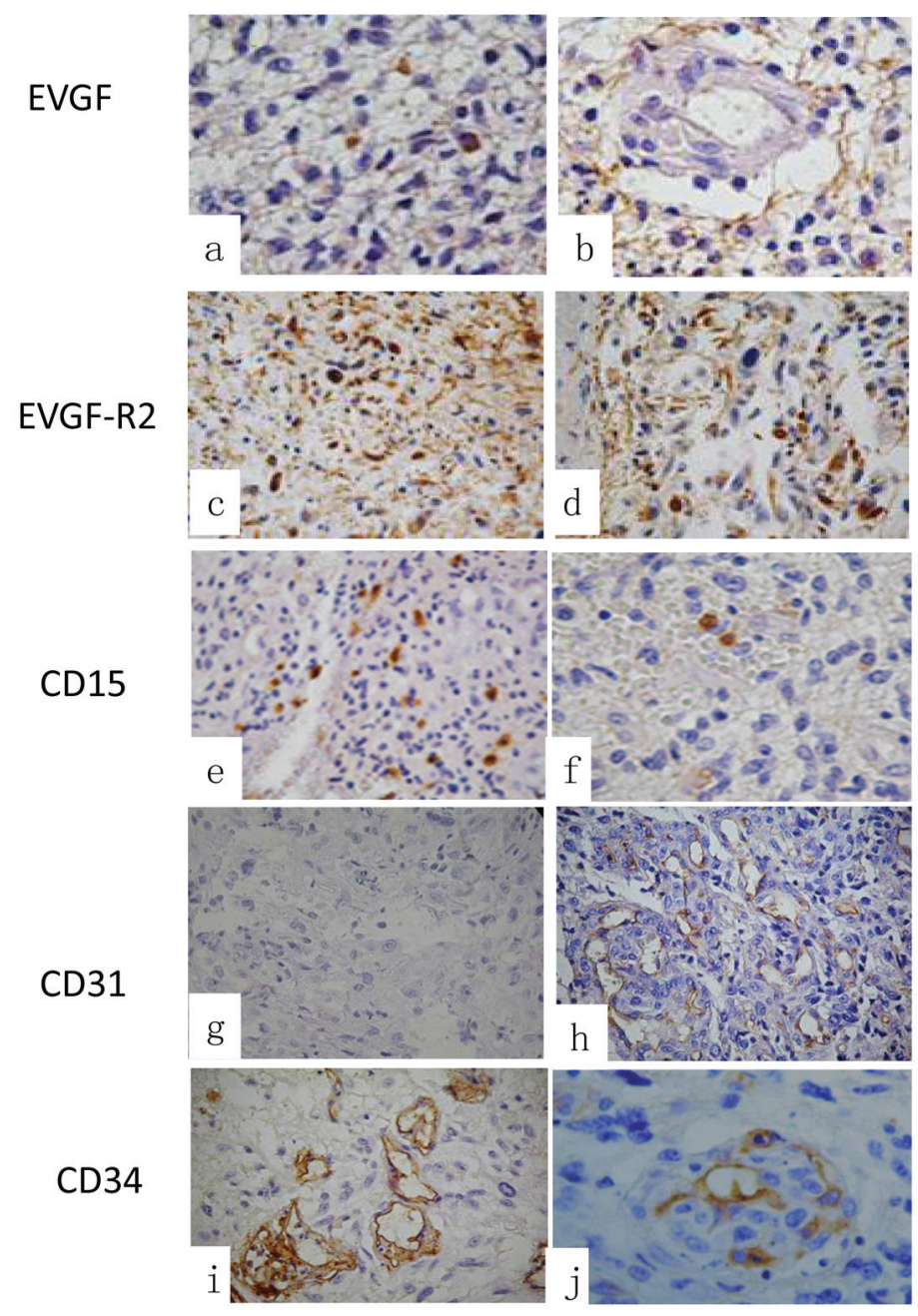

Figure 2. Immunohistochemistry of the different primary antibodies used: (a) expression of EVGF in tumoral cells and in (b) perivascular cells EVGF positive cells. (c) EVGF-R2 immunoexpression in tumoral cells and in (d) in perivascular cells positive reaction. (e) The immunoexpression of CD15 in tumoral cells and in (f) perivascular and endothelial cells. (g) CD31 expression of tumoral cells and in ( $h$ ) perivascular and endothelial cells. (i) The expression of CD34 in tumoral areas and in (j) perivascular and endothelial cells immunoreaction (original magnification $\times 400$ ).

There was a statistical correlation between perivascular positive cells with GFAP- $\delta(\mathrm{P}=0.000)$; however, there was a higher expression for CD15, nestin and VEGF-R2 in primary than in secondary. In relation with tumoral cell expression, there was a higher expression of nestin and VEGF-R2 in primary tumors than in secondary without a statistical relevance.

\section{Discussion}

Angiogenesis is regarded as a hallmark of cancer progression and it has been postulated that solid tumor growth depends on angiogenesis. However, it is clear that tumor cell invasion can occur without angiogenesis, a phenomenon that is particularly evident by the infiltrative growth of malignant brain tumors, such as GBM, one of the most important morphologic features of glioblastoma in the presence of microvascular proliferation to promote tumor initiation and progression $[1,9]$. Cancers likely originate in progenitor zones containing stem cells and perivascular stromal cells. Much evidence suggests that stromal cells play a central role in tumor initiation and progression. Brain perivascular cells (pericytes) are contractile and function normally to regulate vessel tone and morphology, have stem cell properties, are interconvertible with macrophages and are involved in new vessel formation during angiogenesis [9]. The presence of glomeruloid vessels is part of the histologic diagnostic criteria in the current WHO classification for glioblastoma [1]. The angiogenesis in glioblastoma represents a response to hypoxia in the neoplastic microenvironment and is frequently found in surrounding areas of pseudopalisading necrosis [9]. Furthermore, evidence for GBM cell/pericyte fusion-hybrids, some of which are lo- 
Table 3. Immunoexpression of Primary Antibodies and Labeling Index in Perivascular and Tumoral Areas According to Primary vs. Secondary Tumors

\begin{tabular}{lllllll}
\multirow{2}{*}{ Primary antibodies } & \multicolumn{2}{c}{ Primary tumors } & & \multicolumn{3}{c}{ Secondary tumors } \\
\cline { 2 - 3 } CD31 & Perivascular cells & Tumoral cells & & Perivascular cells & Tumoral cells & P value \\
CD34 & 65.00 & 2.00 & 62.00 & 2.00 & 0.037 \\
CD15 & 69.00 & 2.00 & 70.00 & 2.00 & 0.030 \\
Factor VIII & 2.0 & 0.00 & 1.5 & 0.00 & 0.261 \\
Vimentin & 6.00 & 1.50 & 5.00 & 1.00 & 0.231 \\
GFAP & 65.64 & 50.00 & 62.00 & 50.00 & 0.043 \\
Nestin & 6.00 & 70.00 & 8.50 & 70.00 & 0.285 \\
GFAP- $\delta$ & 78.00 & 43.00 & 71.00 & 42.00 & 0.275 \\
EVGF & 75.00 & 2.00 & 70.00 & 1.50 & 0.000 \\
EVGF-R2 & 62.00 & 3.00 & 63.00 & 2.00 & 0.005 \\
$\beta$ FGF & 74.50 & 1.50 & 71.00 & 62.00 & 2.00 & 0.000 \\
\hline
\end{tabular}

In all primary antibodies were evaluated by median.

cated on abnormally constricted vessels ahead of the tumor and linked to tumor-promoting hypoxia. Hypoxia leads to an increase in angiogenic factors, including VEGF that results in microvascular hyperplasia and endothelial sprouting from pre-existing vessels $[3,9,10]$. Rafat et al (2010) [11] found that the serum levels of VEGF, $\beta F G F$, endostatin, and thrombospondin-1 in glioblastoma patients did not predict survival. Ricci-Vitiani et al (2010) [3] found CD31 positive endothelial cells to label with p53 protein and in double immunofluorescence/FISH experiments reported alterations in chromosomes $10,19 q$ and $22 q$ in neoplastic cells and a subset of endothelial cells. Although previous reports suggest that GSCs may give rise to ECs in GBMs [3]. In addition, recent studies support the induction of angiogenesis by human glioma stem cells, mediated in part by hypoxia and suggest that perivascular stem cell niches can play an important role in brain tumor pathobiology [3, 12-16]. Asahara et al (1997) [17] published the first detailed description of isolation of putative progenitor endothelial cells for angiogenesis. A possible mix of both early progenitor and endothelial phenotype is $\mathrm{CD} 133^{+} / \mathrm{CD} 34^{+} / \mathrm{VEGFR}^{2} 2^{+}$cells, which do not express vascular endothelial cadherin and von Willebrand factor [3, 13]. Mature EPCs are found that obviously have lost CD133 but are positive for CD34 and VEGFR2 $[18,19]$. Mature ECs show a high expression of VEGF-R2, E-cadherin, and von Willebrand factor. Using a variety of molecular markers, Rodriguez et al (1998) [20] demonstrated that neoplastic cells did not contribute significantly to the endothelial-lined vasculature of primary human glioblastoma and suggested that until recently, it was thought that blood vessels and other stromal elements were recruited into the growing tumor from non-neoplastic sources [20]. Cheng et al (2013) [7] determined the significance of GSC derived into pericytes maintaining functional vessels to support GBM tumor growth. Further, pericytes are similar to mesenchymal stem cells (MSCs) [6, 7]. Vascular pericytes play critical roles in various pathological conditions: support of vascular structure and function, mainte- nance of blood-brain barrier, facilitation of vessel maturation and initiation of vessel sprouting [15-17, [20]. GSCs promote tumor angiogenesis through elevated expression of VEGF [9, 17]. GSCs are often located in perivascular niches and interact with endothelial cells in a bidirectional manner. There is enough evidence to consider GSCs as potential pericyte progenitors. GSCs have the ability to undergo mesenchymal differentiation $[3,16,18-20]$.

They are essential for glioma invasion and vasculogenesis processes. It is hypothesized that irradiated normal brain tissues promote tumor invasion and vasculogenesis, resulting in glioma recurrence $[2,20]$.

Nestin is reported to be expressed in repair processes, various neoplasms and proliferating vascular endothelial cells and is also expressed in non-neuronal immature or progenitor cells in some normal tissues $[8,14]$. Using nestin to more accurately evaluate microvessels density in cancer specimens may be a novel prognostic indicator [14]. Furthermore, nestintargeted therapy may suppress tumor proliferation via inhibition of angiogenesis in numerous malignancies [14]. We found a significant statistical correlation between perivascular nestin with CD31, perivascular and VEGF-R2 positive cells, patient death and recurrence. One isoform of GFAP- $\delta$ is expressed by proliferative radial glia in the developing human brain. In the adult GFAP- $\delta$ is a marker for neural stem cells. During development, the GFAP- $\delta$ is expressed by radial glia, as denoted by the co-expression of markers like vimentin and nestin. GFAP- $\delta$ is also expressed in other astrocytic populations during development [15]. GFAP- $\delta$ marks both neural stem cells and mature astrocytes $[15,17]$. We observed a significant statistical correlation between GFAP- $\delta$ in relation with high levels of MIB-1 and positive perivascular cells. We also note that the recurrence of tumors was in relation with treatment type, CD34-MVD, EVGF in perivascular cells and EVGF-R2 immunoexpression in tumor cells. Primary GBM as well as in older patients had a shorter follow-up than in secondary and at 

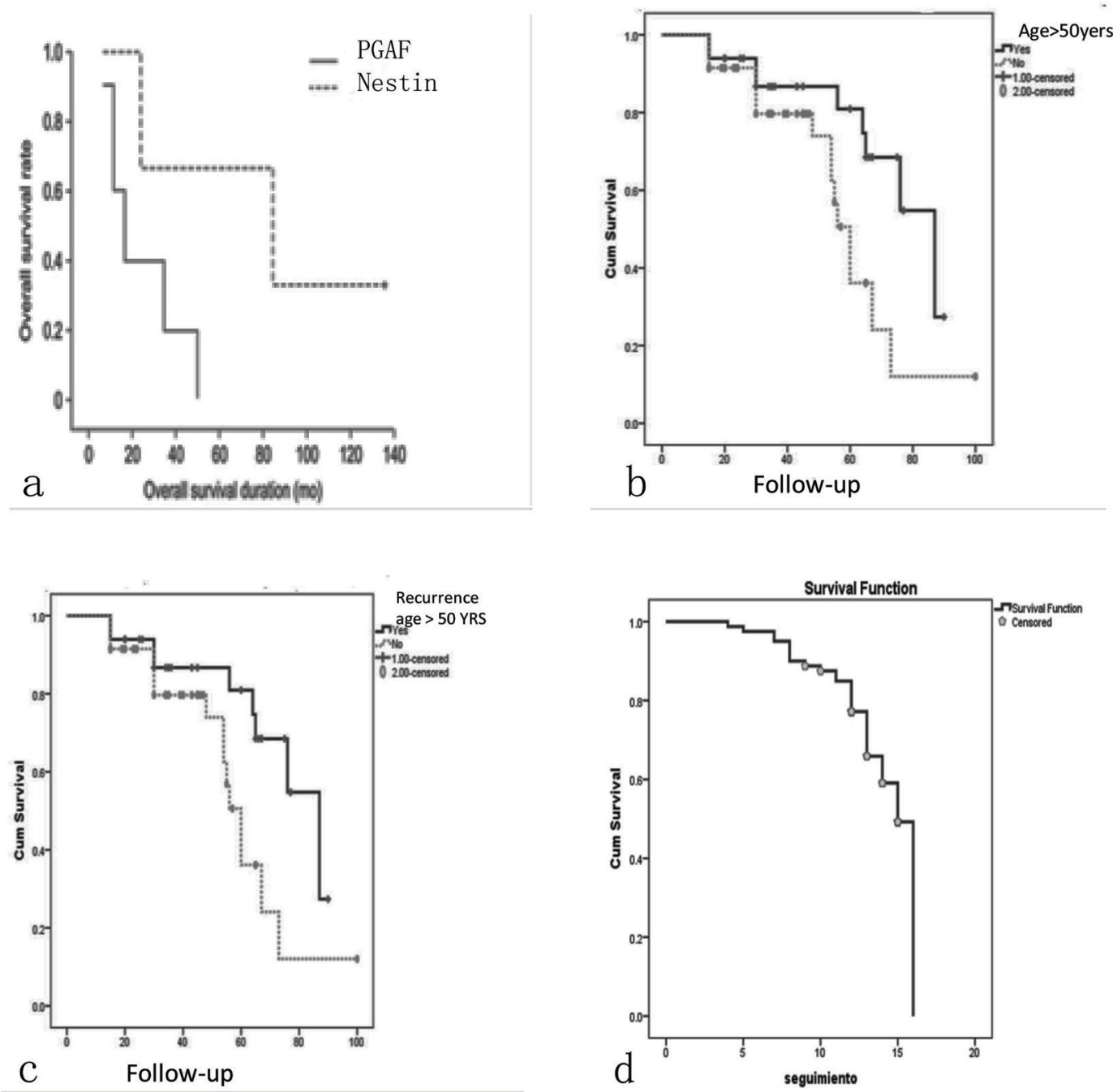

Figure 3. Kaplan-Meier curves stratified by follow-up and survival. (a) Kaplan-Meier curves stratified with nestin and GFAP immunoexpression correlation ship and the follow-up of the patients. (b) The curve of the relation between patients $<50$ years and $>50$ years and survival. (c) The curve stratified by recurrence and follow-up and in (d) the survival of the all patients, the median survival at 15 months.

younger age. Recently study showed that the DNA sequencing analysis disclosed that p53-positive microvascular proliferation cells exhibited TP53 mutations identical to those observed in the original tumor; p53-negative microvascular proliferation cells contained a normal allele, and concluded that some microvascular proliferation clusters in GBM result from mesenchymal transition [21].

Angiogenesis in glioblastoma biology and an anti-angiogenic agent are under clinical investigation with promising results actually. Avastin (bevacizumab) works and is approved for treatment of recurrent GBM [2]. There are several papers in the literature describing its therapeutic properties. However, the angiogenic profiles of patients with glioblastoma and their clinical significance are not well understood $[2,20]$.

\section{Conclusions}

We observed that glioblastomas are tumors which can present with immature cells around vessels not properly in endothelial cells causing worse prognosis and secondary tumors and patients over 50 years had worse prognosis than primary one.

\section{Acknowledgement}

The authors want to thank Dr. Fausto J. Rodriguez for his critically reviewing of the manuscript and helpful suggestions. 


\section{Conflicts of Interest}

There is no conflict of interest.

\section{Grant Support}

None.

\section{Abbreviations}

GBM: glioblastoma multiforme; WHO: World Health Organization; GSC: glioma stem cell; TMZ: DNA alkylating agent temozolomide; LI: MIB-1 labeling index; MVD: microvascular density; EVGF: endothelial vascular growth factor; EVGFR2: endothelial vascular growth factor receptor 2; VIII factor: von Willebrand's factor; GFAP: glial fibrillary acidic protein; GFAP- $\delta$ : GFAP delta; PBS: phosphate buffer solution; MRI: magnetic resonance imaging; PFS: progression-free survival; OS: overall survival

\section{References}

1. Louis DN, Ohgaki H, Wiestler OD, Cavenee WK, Burger PC, Jouvet A, Scheithauer BW, et al. The 2007 WHO classification of tumours of the central nervous system. Acta Neuropathol. 2007;114(2):97-109.

2. Stupp R, Mason WP, van den Bent MJ, Weller M, Fisher B, Taphoorn MJ, Belanger K, et al. Radiotherapy plus concomitant and adjuvant temozolomide for glioblastoma. N Engl J Med. 2005;352(10):987-996.

3. Ricci-Vitiani L, Pallini R, Biffoni M, Todaro M, Invernici G, Cenci T, Maira G, et al. Tumour vascularization via endothelial differentiation of glioblastoma stem-like cells. Nature. 2010;468(7325):824-828.

4. Hanahan D, Folkman J. Patterns and emerging mechanisms of the angiogenic switch during tumorigenesis. Cell. 1996;86(3):353-364.

5. Takeuchi H, Hashimoto N, Kitai R, Kubota T, Kikuta K. Proliferation of vascular smooth muscle cells in glioblastoma multiforme. J Neurosurg. 2010;113(2):218-224.

6. Folkins C, Shaked Y, Man S, Tang T, Lee CR, Zhu Z, Hoffman RM, et al. Glioma tumor stem-like cells promote tumor angiogenesis and vasculogenesis via vascular endothelial growth factor and stromal-derived factor 1. Cancer Res. 2009;69(18):7243-7251.

7. Cheng L, Huang Z, Zhou W, Wu Q, Donnola S, Liu JK, Fang X, et al. Glioblastoma stem cells generate vascular pericytes to support vessel function and tumor growth. Cell. 2013;153(1):139-152.

8. Matsuda Y, Hagio M, Ishiwata T. Nestin: a novel angiogenesis marker and possible target for tumor angiogenesis. World J Gastroenterol. 2013;19(1):42-48.

9. Brat DJ, Van Meir EG. Glomeruloid microvascular proliferation orchestrated by VPF/VEGF: a new world of angiogenesis research. Am J Pathol. 2001;158(3):789-796.

10. Kaur B, Tan C, Brat DJ, Post DE, Van Meir EG. Genetic and hypoxic regulation of angiogenesis in gliomas. $\mathrm{J}$ Neurooncol. 2004;70(2):229-243.

11. Rafat N, Beck G, Schulte J, Tuettenberg J, Vajkoczy P. Circulating endothelial progenitor cells in malignant gliomas. J Neurosurg. 2010;112(1):43-49.

12. Li Z, Bao S, Wu Q, Wang H, Eyler C, Sathornsumetee $\mathrm{S}$, Shi Q, et al. Hypoxia-inducible factors regulate tumorigenic capacity of glioma stem cells. Cancer Cell. 2009; 15(6):501-513.

13. Calabrese C, Poppleton H, Kocak M, Hogg TL, Fuller C, Hamner B, Oh EY, et al. A perivascular niche for brain tumor stem cells. Cancer Cell. 2007;11(1):69-82.

14. Fischer I, Gagner JP, Law M, Newcomb EW, Zagzag D. Angiogenesis in gliomas: biology and molecular pathophysiology. Brain Pathol. 2005;15(4):297-310.

15. Heo DH, Kim SH, Yang KM, Cho YJ, Kim KN, Yoon DH, Kang TC. A histopathological diagnostic marker for human spinal astrocytoma: expression of glial fibrillary acidic protein-delta. J Neurooncol. 2012;108(1):45-52.

16. deCarvalho AC, Nelson K, Lemke N, Lehman NL, Arbab AS, Kalkanis S, Mikkelsen T. Gliosarcoma stem cells undergo glial and mesenchymal differentiation in vivo. Stem Cells. 2010;28(2):181-190.

17. Asahara T, Murohara T, Sullivan A, Silver M, van der Zee R, Li T, Witzenbichler B, et al. Isolation of putative progenitor endothelial cells for angiogenesis. Science. 1997;275(5302):964-967.

18. Crisan M, Yap S, Casteilla L, Chen CW, Corselli M, Park TS, Andriolo G, et al. A perivascular origin for mesenchymal stem cells in multiple human organs. Cell Stem Cell. 2008;3(3):301-313.

19. Armulik A, Genove G, Mae M, Nisancioglu MH, Wallgard E, Niaudet $\mathrm{C}, \mathrm{He} \mathrm{L}$, et al. Pericytes regulate the blood-brain barrier. Nature. 2010;468(7323):557-561.

20. Cines DB, Pollak ES, Buck CA, Loscalzo J, Zimmerman GA, McEver RP, Pober JS, et al. Endothelial cells in physiology and in the pathophysiology of vascular disorders. Blood. 1998;91(10):3527-3561.

21. Kawasoe T, Takeshima H, Yamashita S, Mizuguchi S, Fukushima T, Yokogami K, Yamasaki K. Detection of p53 mutations in proliferating vascular cells in glioblastoma multiforme. J Neurosurg. 2015;122(2):317-323. 